\title{
АНАЛИЗ ДИАЛЕКТИЗМОВ В ПРОИЗВЕДЕНИЯХ МО ЯНЯ И СПОСОБЫ ИХ ПЕРЕВОДА С КИТАЙСКОГО ЯЗЫКА НА РУССКИЙ
}

\section{ANALYSIS OF DIALECTICISMS IN THE WORKS OF MO YAN AND THEIR METHODS OF TRANSLATION FROM CHINESE INTO RUSSIAN}

Dou Jing

Summary: The use of dialecticisms is a feature of Mo Yan's work, their use not only increases the artistic expressiveness of novels, but also reflects the local social culture. The article provides a classification of the dialecticisms used in the works of Mo Yan, analyzes their funtions and reasons for usage, discusses specific examples of dialecticisms in the Russian translation and summarizes the ways of their translation.

Keywords: dialecticism, classification, function, Mo Yan, translation.
马 иалектизм показывает культурную традицию определенного региона. Под диалектизмами понимаются диалектные слова, употребляющиеся в художественной литературы как средство стилизации слога [2, с. 131].

В настоящее время диалектизмы часто включаются авторами в текст художественного произведения. В китайских литературных кругах считается, что Мо Янь наиболее часто использует диалектизмы в своем литературном творчестве. Любой диалектизм привносит в текст оттенок простонародности и провинциальности [1, с. 203]. В связи с этими стилистическими особенностями Мо Янь называет себя провинциальным писателем, свои произведения провинциальной литературой.

Как отметил Мо Янь, язык, употребляемый писателем, должен быть свойствен самому себе и отличать автора от других писателей [12, с. 30]. Мо Янь родился в уезде Гаоми провинции Шандун, здесь он провел свое детство и юность. Из-за культурной революции Мо Янь перестал учиться и начал крестьянствовать. Своими глазами писатель увидел тяжелую и бедную жизнь крестьян. Жизненный опыт предоставил ему творческий материал, любовь к родине и сочувствие родным оказали сильное влияние на формирование его творческого и языкового стиля. Основными темами его произведений стали жизненные трудности и несправедливость. В своих романах он много раз употребляет шаньдунский диалект, чтобы читатели могли по-настоящему ощущать жизнь китайских крестьян и узнать региональную культуру уезда Гаоми.

\author{
Доу Цзин \\ Докторант, Уханьский университет, г. Ухань, КНР \\ 15071235606@163.com
}

Аннотация: Использование диалектизмов является особенностью творчества Мо Яня, их употребление не только повышает художестввенную выразительность романов, но и отражает местную социальную культуру. В статье проводится классификация диалектизмов, использованных в произведениях Мо Яня, анализируются их функции и причины использования, рассматриваются конкретные примеры диалектизмов в русском переводе и обобщаются способы их перевода.

Ключевые слова: диалектизм, классификаци, функции, Мо Янь, перевод.

Чтобы лучше понимать языковой стиль Мо Яня и узнать особенности шаньдунского диалекта, в статье исследуются три его произведения $\mathrm{Q}$ «Красный гаолян», «Устал рождаться и умирать», «Большая грудь, широкий зад», проводится классификация диалектизмов по их принадлежности к частям речи, включая имя существительное, глагол, имя прилагательное, звукоподражательное слово, частицу и междометие.

Диалектные существительные являются самыми частотными частями речи в произведениях Мо Яня, в их состав входят животные, растения, одежда, пища, обращения, приборы и так далее. Например: 下货'грязные делишки', 鳖窝'черепашье гнездо', 体己钱'скудная наличность'. Кроме того, в романах часто встречаются диалектизмы в формате морфема+子, в этой словообразовательной структуре 子-это суффикс, который является маркером разговорной речи, его употребление не изменяет значения основы слова. Например:老妈子'пожилые женщины', 叫花子'попрошайка', 嫚姑子'девка'. Такие слова содержат определенную эмоциональную окраску и создают уникальную диалектную атмосферу.

Диалектные глаголы выражают способ производства, систему ценностей и образ жизни жителя определенного района [8, с. 7]. В произведениях Мо Яня глагольные диалектизмы имеют следующие специфические черты: во-первых, значения глаголов связаны с действиями животных; во-вторых, диалектизмы часто содержат имплицитный смысл; в-третьих, писатель предпочитает использовать односложные глаголы. Например:

1. 而现在, 他们一定在胡同里成群结队地奔跑着, 
追逐着妇女和儿还像撒欢的马驹一样垉蹰子、喷 德响 $[9$, c. 9]。

А сейчас, наверное, мчатся толпой по проулкам, преследуя женщин и детей, взбрыкивая и храпя, как жеребцы [5, с. 28].

2. 她能飞檐走壁、含沙射影, 掏包割口袋的技巧更 是炉火纯青, 出神入化 $[9$, c. 313]。

Она может запрыгивать на крыши и ходить по стенам, а по части ловкости рук, искусному вытаскиванию кошельков и разрезанию карманов достигла совершенства [5, с. 590].

3. 在这一犹豫间, 主人扽住缰绳一扯, 我的前蹄降 落在母驴的身后 [6, c. 33]。

Пока я колебался, хозяин дернул за веревку, и мои передние ноги опустились радом с крупом ослицы [11, с. 51].

В шаньдунском диалекте имя прилагательное обычно употребляется в формах 'ABB', 'AABB', 'ABAB', как 湿 漉漉 'мокрый', 红红绿绿'красный и зеленый', 唰啦唰 啦'ритмичный'. Эти слова относятся к разговорному языку, повторение слогов соответствует речевой привычке жителей и сильнее выражает их эмоции.

Диалектные звукоподражательные слова служат человеку для представления звучащей действительности, помогая более точно, более ярко отразить в речи характерные признаки того или иного предмета или явления $[4$, c. 16]. Они делают текст более живым и интересным, например: 滴滴答答入槩内'с журчанием заструиться внутрь', 咻咻喘气'шумно дышать', 咕咚咕咚喝了'с бульканьем выпить'.

Диалектные частицы и диалектные междометия в романах Мо Яня обычно встречаются в диалогах персонажей, находятся в начале или конце предложений. Они являются важными средствами для прямой передачи отношений и эмоций персонажей. Например:

1. 余司令从前边回来, 蹲下, 捏着王文义的脖子, 压低嗓门说: “别叫, 再叫我就毕了你 [10, c. 9]!" Командир Юй вернулся, присел на корточки, схватил Ван Вэньи за горло и, понизив голос, прошипел:

- Ну-ка умолкни, не то я тебя прикончу [3, с. 17]!

2. 我原想省下这两瓶酒一个猪头, 烸, 该花的省不 下，叫去吧 $[9$, c. 10]! "

Эx, думала сэкономлю пару бутылей вина да свиную голову, но, видать, придётся потратиться [5, с. 28].

Диалектизмы играют важную роль в произведениях Мо Яня. В качестве средства повествования они вызывают большой интерес у читателей, так как приближены к общественной жизни. К числу главных функций можно отнести к следующие:
Во-первых, диалектизмы имеют существенное значение в изображении внешности, характера, эмоционального состояния персанажей. Мо Янь - мастер языка, диалектизмы в его произведениях всегда точно соответствуют статусу и характеру персанажей. Он успешно создал много таких женских образов, как самостоятельная Дай Фэнлянь в романе «Красный гаолян», упорная Шангуань Лу и своевольная Шангуань Люй в романе «Большая грудь, широкий зад».

Во-вторых, диалекты, подобно любому языку, постоянно изменяются. Диалектизмы, относящиеся к разному времени, могут восстанавливать фон события и верно изображать сюжеты определенного исторического периода. «Красный гаолян» является одним из самых известных произведений Мо Яня, в котором рассказывается о том, как люди, живущие в уезде Гаоми провинции Шаньдун, борются с японскими захватчиками. В этом романе крестьяне в соответствии с внешним видом и местом производства оружия называют его такими диалектизмами, как 乌枪'длинноствольное ружье', 老汉 阳'старенькие «ханьяны» винтовка«Манлихер»'. Хотя эти диалектизмы уже устарели, но в романе таким образом переданы черты эпохи.

B-третьих, диалектизмы в романах Мо Яня в основном касаются питания, праздников, орудий производства, жилищной обстановки, свадебных или траурных церемоний, взгляда на рождаемость и межличностные отношения. Они эффективно способствуют знакомству читателей с обычаями, менталитетом и бытовыми привычками народа провинции Шаньдун и распространяют региональную культуру.

В связи с разницей в языковом и культурном планах перевод диалектизмов всегда создает немало трудностей для переводчиков. В. Н. Комиссаров полагает, что использование в оригинале форм таких диалектов может иметь двоякий характер. С одной стороны, диалект может представлять собой вид языка, используемого в процессе общения, то есть выступать в качестве исходного языка. С другой стороны, диалектные формы могут употребляться с целью языковой характеристики отдельных персонажей [7, с. 75]. Проанализировав конкретные примеры с учетом целей использования диалектизмов в русских переводах произведений Мо Яня, мы пришли к следующему выводу: основными способами их передачи являются буквальный, вольный и описательный переводы, например:

1. 我伸出一只手指, 指点着洪泰岳那件五冬六夏都 不换洗的制服补子上那个鼓鼓囊囊的口袋 $[11 ，$ c. 269]。

Я указал на оттопыренный карман френча, который он не снимал и не стирал пять зим и шесть лет [6, c. 51].

2. 过了今天, 就不要管明天, 这驴日的岁月, 没有 
几天折腾头了, 早折腾完了, 早吹灯拔蜡 $[11, \mathrm{c}$. 84]。

Прожил сегодняшний день, и нечего думать о завтрашнем. Нынче время поганое, можно и пары дней не прожить, как уже и крышка. Как говорится, гаси фонарь, задувай свечу [6, с. 117].

3. 轿夫们的话更加粗野了, 他们有的骂我曾外祖父 是个见钱眼开的小人, 有的说鲜花插到牛粪上 [10, с. 41]。

Носильщики стали говорить ещё грубее: некоторые поносили моего дедушку, малодушный, мол, человечишка, про каких говорят «при виде денег и у слепого глаза открываются», некоторые намекали, дескать, свежий цветок воткнут в навозную кучу [3, с. 60].

В вышеуказанных примерах 五冬六月 означает'слишком длинное время', 鲜花插到牛粪上символизирует 'неравный брак', 早吹灯拔蜡 подразумевает 'ранний срок окончания работы.' Переводчики буквально переводят эти диалектизмы, сохраняют гиперболу и сравнение исходного текста, как 'пять зим и шесть лет', 'свежий цветок', 'навозная куча'. Этот способ передает образность и провинциальность исходного текста, в то же время увеличивает силу воздействия переводного текста.

4. 她欣慰地说: “谢天谢地, 总算开了腚了。求菩萨 保佑，明年送我家个孙子吧 [9, c. 410]。"

- Слава небу и земле! - удовлетворённо возгласила она. - Наконец-то дело пошло. Оборони нас, бодхисатва, и пошли нашей семье на будущий год внука [5, с. 760].

5. 余司令怒冲冲地骂: “舅子, 你打出王旅的旗号也 吓不住我。老子就是这地盘上的王, 吃了十年拤 饼, 还在乎王大爪子那个驴日的 [10, с. 24]! " Командир Юй принялся браниться:- Ты, братишка, меня не напугаешь знамёнами бригады Вана. Я здесь главный, десять лет разбойничаю, и плевать я хотел на этого гребаного Большелапого Вана [3, с. 38]!

6. 都给我闭上臭嘴, 当心我把你们那点下货给抖擞 出来 $[9$, c. 336]。

- А ну позакрывали рты свои поганые, не то все узнают о ваших грязных делишках [5, с. 628]!

开了腚了 является диалектным вульгаризмом и переводится буквально как задница открывается, что означает 'рожать детей'. 拤饼 это местная пища уезда Гаоми, 吃 拤饼一'есть круглую лепёшку', 下货 - 'внутренние органы животных', но в данном контексте они обозначают разбойничать и грязные делишки соответственно. Эти диалектные слова часто встречаются в разговорной речи необразованного человека, но в этом контексте имеют свои переносные значения. В рассмотренных примерах переводчики используют вольный перевод, выбирают разговорные слова, чтобы максимально передать речевые характеристики персонажей и устранить препятствие понимания для читателей.

7. 我的主人抓着他的腕子不放松, 暗中使上了力 气，使那天天搞“破鞋”淘虚了身子的杨七连声哎吆 着, 手里的藤条也落在地上 [11, c. 28]。

Его запястья хозяин не отпускал, а незаметно сжал покрепче, да так, что этот молодчик, растративший себя на развлечения с потаскухами, заскулил от боли, а лозина выпала из руки [6, с. 44].

8. 传说孙大姑年轻时能飞檐走壁, 是江湖上有名的 女响马, 只因犯了大案, 才下嫁给孙小炉匠 [9, c.11]。

Про неё говаривали, что в молодости она ловко ходила по крышам и перепрыгивала через стены, промышляла в округе грабежами да и замуж за печника Суня вышла, лишь когда ею всерьёз заинтересовался закон [5, с. 32].

9. 接手家业时虽逢乱世, 既要应付游击队, 又要应 付黄皮子 [11, с. 10]。

Время, когда я принял на себя дела, было лихое, приходилось приспосабливаться и к партизанам, и к «крысам желтопузым» $[6$, с. 16].

Комментарий: так называли солдат марионеточного китайского корпуса японской армии.

Очевидно, что во всех трех примерах используется описательный перевод. 搞破鞋 обозначает 'внебрачные любовные отношения', 响马 и 黄皮子 это клички людей. Общей чертой этих трех диалектизмов является то, что они имеют негативный смысл. В русском языке нет соответствующих диалектизмов, поэтому они передаются русскими общелитературными словами, объясняются внутри переводного текста или дополняются комментарием. Описательный перевод позволяет достигнуть содержательного соответствия и сохраняет культурную специфику.

Произведения Мо Яня имеют яркие языковые особенности и своеобразное художественное воздействие. Анализ трех главных романов Мо Яня позволяет сделать следующие выводы: диалектные слова в них можно разделить на пять таких видов как имя существительное, глагол, имя прилагательное, звукоподражательное слово, частица и междометие. В качестве средства художественной выразительности они способны передавать черты эпохи, описывать внешность, характер и эмоции персонажей. Но в связи со свойственной диалектизмам культурной информацией и стилистической окраской перед переводчиком встает сложная задача. В русском переводе произведений Мо Яня основными способами перевода служат буквальный, вольный и описательный переводы. Эти способы верно передают прямое и переносное значения диалектизмов исходного текста, достигают их стилистических целей в переводном тексте. 


\section{ЛИТЕРАТУРА}

1. Алексеева И.С. Введение в переводоведение. М.: Академия, 2002. 352 с.

2. Ахманова 0.С. Словарь лингвистических терминов. М.: Советская энциклопедия, 1969.607 с

3. Власова Н.В. Красный гаолян. М.: Текст, 2018. 476 с.

4. Григорьева П.И. Березуцкая Д.О. Особенности звукоподражаний в английском языке // Актуальные проблемы гуманитарных и естественных наук. Москва: Научное издательство «Институт стратегических исследований», 2017. С. 16-18

5. Егоров И.А. Большая грудь, широкий зад. М.: Амфора, 2013.831 с.

6. Егоров И.А. Устал рождаться и умирать. М.: Амфора, 2014. 701 c.

7. Комиссаров В.Н. Современное переводоведение. М.: ЭТС, 2002. 420 с.

8. 金静. 莫言小说《丰乳肥臀》文学语言研究. 西安: 陕西师范大学. 2015.47页(Цзинь Цзин. Исследование языка художественной литературы (на материале романа Мо Яня «Большая грудь, широкий зад»): дис. ... канд. филол. наук. М., 2015. 47 с.)

9. 莫言. 丰乳肥臀. 北京： 中国工人出版社. 2003. 450页 (Мо Янь. Большая грудь, широкий зад. М.: Китайское рабочее издательство, 2003.450 с.)

10. 莫言. 红高粱. 上海: 上海文艺出版社. 2012.364页 (Мо Янь. Красный гаолян. М.: Шанхайское издательство литературы и искусства, 2012.364 с.)

11. 莫言. 生死疲劳. 上海: 上海文艺出版社. 2012. 543页 (Мо Янь. Устал рождаться и умирать. М.: Шанхайское издательство литературы и искусства, 2012.543 с.)

12. 施旸. 莫言作品中的方言特点及作用研究. 河南: 开封教育学院学报. 2016. 第36卷第2期. 30-31页(Ши Ян. Анализ характеристик и функций диалектов в работах Мо Яна // Вестник Института образования Кайфэн. Хэнань: Вестник Института образования Кайфэн, 2016. № 2. С. 30-31.)

() Доу Цзин (15071235606@163.com).

Журнал «Современная наука: актуальные проблемы теории и практики»

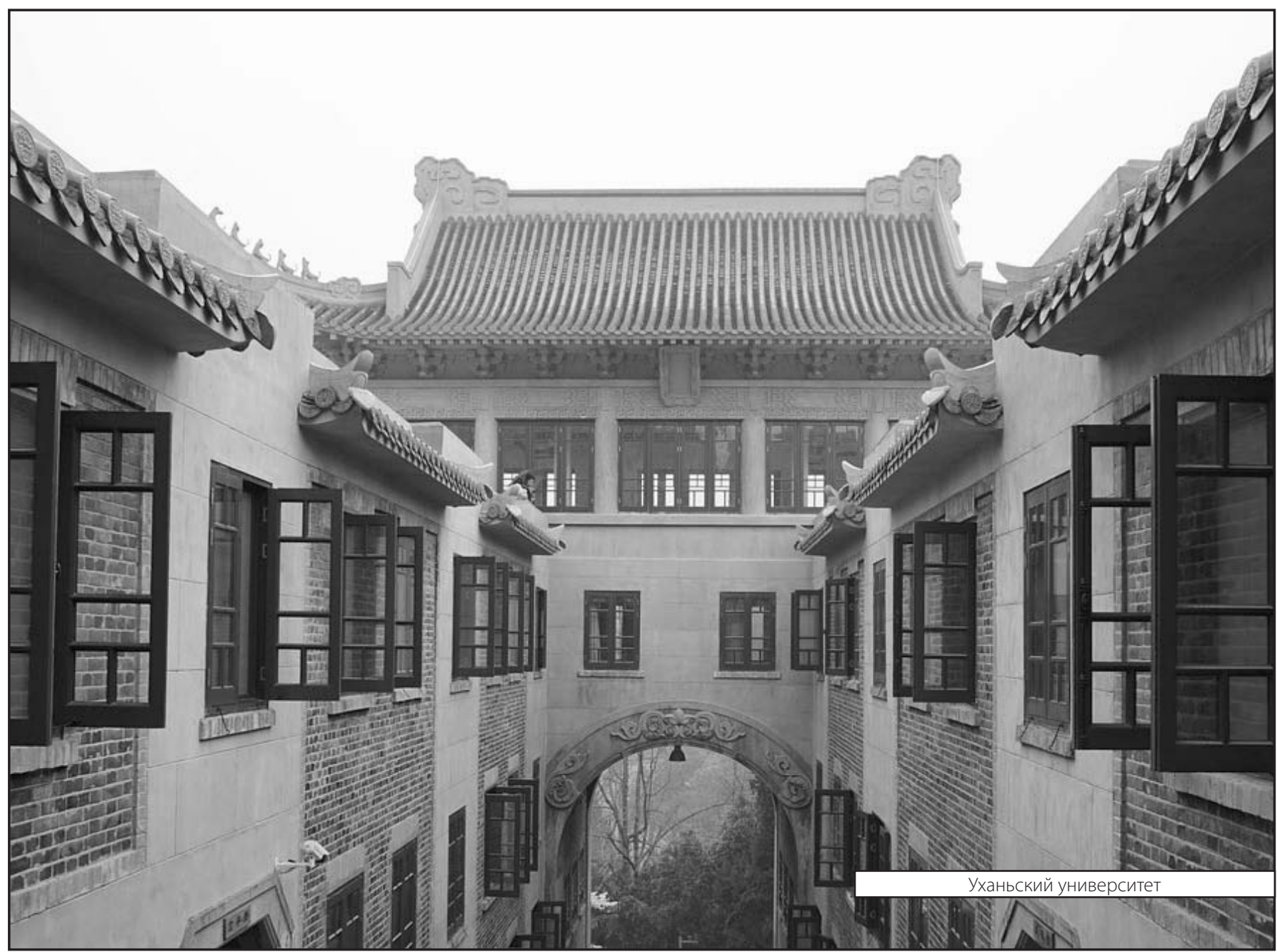

